Article

\title{
Evaluating the Environmental Performance of a Product/Service-System Business Model for Merino Wool Next-to-Skin Garments: The Case of Armadillo Merino ${ }^{\circledR}$
}

\author{
Nynne Marie Bech ${ }^{1}$, Morten Birkved ${ }^{2}{ }^{-}$, Fiona Charnley ${ }^{3}{ }^{-}$, Louise Laumann Kjaer ${ }^{4}$, \\ Daniela C. A. Pigosso ${ }^{4}$ (D), Michael Z. Hauschild ${ }^{5}$, Tim C. McAloone ${ }^{4}$ and Mariale Moreno ${ }^{6, *(D)}$ \\ 1 NIRAS Gruppen A/S. Sortemosevej 1. DK-3450 Allerød, Denmark; nynnebech@gmail.com \\ 2 Institute of Chemical Engineering, Biotechnology and Environmental Technology, Faculty of Engineering, \\ University of Southern Denmark, Campusvej 55 Odense M-DK-5230, Denmark; morb@kbm.sdu.dk \\ 3 University of Exeter Business School, University of Exeter, Rennes Drive Exeter EX4 4PU, UK; \\ F.Charnley@exeter.ac.uk \\ 4 Section of Engineering Design and Product Development, Department of Mechanical Engineering, \\ Technical University of Denmark, Kongens DK-2800 Kgs, Lyngby, Denmark; danpi@dtu.dk (D.C.A.P.); \\ tmca@dtu.dk (T.C.M.); lodo@lodo.dk (L.L.K.) \\ 5 Department of Technology, Management and Economics, DTU Management, \\ Technical University of Denmark, Akademivej, Building 358 DK-2800 Kgs. Lyngby, Denmark; mzha@dtu.dk \\ 6 Centre for Competitive Creative Design (C4D), Cranfield University, College Road, Cranfield MK43 0AL, UK \\ * Correspondence: mariale8@gmail.com; Tel.: +44-(0)-1234-750111 (ext. 2140)
}

Received: 29 July 2019; Accepted: 8 October 2019; Published: 22 October 2019

check for updates

\begin{abstract}
Circular business models are often enabled by means of product/service-systems (PSS). The common perception is that such business models have enhanced environmental performance when compared to conventional business models rooted in the linear economy. This article investigates the environmental potential of developing a use-oriented PSS business model for Merino wool t-shirts intended for use by the British Ministry of Defence as an alternative to the present supply system based on synthetic $t$-shirts purchased from sportswear clothing companies. To conduct the assessment, we apply the life cycle assessment (LCA) methodology to quantify and compare the climate change impacts and impact potentials of the proposed PSS business model and of a reference business model. Results showed that there could be significant contribution of quantifying environmental potential for PSS business models when justifying the transition to a circular economy. However, when adopting LCA methodology for this purpose, the design of the PSS needs to be well thought to overcome some of the identified challenges. The article concludes by making the case that LCA studies can support the definition, design and value creation of the product/service-systems in early development stages.
\end{abstract}

Keywords: product service system; PSS; circular economy; LCA; merino wool

\section{Introduction}

Circular economy is often seen as an environmental superior alternative to the take-make-dispose linear economy. The circular approach seeks to increase resource efficiency and mitigate environmental impacts while maximising value creation from economic structures [1]. Circular economy literature suggests necessary change to incorporate restoration and recovery at different levels e.g., energy, products, materials, elements or molecules [2], as well as the technical characteristics of modularity, disassembly and repurposing (repair and maintenance); thereby extending product lifetime [3]. Business model innovation is also increasingly key from a circular economy point of view [4]. 
In fact, in recent years, the concept of circular economy has attracted policy makers in the United Kingdom (UK) and Europe, who have been setting up strategies within these regions such as the "Circular Economy Package" launched by the European Commission [5], back in December 2015; and more recently in the UK, a "Circular Economy Strategy" for Scotland [6]. These initiatives provide opportunities to implement circular economy principles on public procurement to expand best practices through better collaborative procurement, guidance and regulations.

The public procurement market is considered the largest business sector in the world and governments have continuously attempted to minimise the negative aspects of consumption through the establishment of sustainable procurement strategies [7]. In an European context, public procurement strategies have moved towards contracts, in which providers deliver services within their product offerings through product/service-systems (PSS) business models [8]. In circular economy literature [9-12], PSS has been acknowledged as one of the archetypes of circular business models, and References [13-15] have argued that a PSS model is potentially superior from an environmental perspective compared to a conventional business model. A PSS is an integrated combination of products and services $[15,16]$ in which suppliers, through a customised contract for availability (CfA), meet the requirements of the contractor [8].

This paper focuses on the provision of a use-oriented PSS to the British Ministry of Defence (MoD). In a use-oriented PSS, there is a shift of ownership of the product, as the manufacturer or retailer retains ownership of it offering a functional "service unit" through leasing or renting the product to the user [17]. Provision of use-oriented PSS business models for complex engineering products such as aircrafts, vessels and vehicles; and its systems (including radars, power packs, armaments, simulators) and subsystems (i.e., engines and arms) to the $\mathrm{MoD}$, has been studied in various publications [8,18-20], all highlighting the benefits of combining the MoD's procurement strategy and PSS. These benefits include closer partnerships between the $\mathrm{MoD}$ and the primary supplier facilitating the share of information and collaboration strategies, sharing risks and reducing costs; as well as better responsiveness from industry to emerging operations scheduled by the MoD [8]. In line with the MoD's current sustainable development strategy contracting, a PSS may also enable the MoD to improve its procurement related environmental performance via PSS strategies that can increase product longevity and reduce resource use; including reuse, refurbishment and recycling $[8,15]$. The focus of current academic literature dealing with the provision of PSS to the MoD has focused on complex engineering products and has not been extended to other more common products, such as clothing. Previous PSS research focusing on the clothing industry [21] has highlighted that PSS business models could be an opportunity to increase garment's quality and longevity with potential to reduce environmental impacts.

Although PSS business models are enhanced as potentially superior from an environmental perspective, Kjaer [22] argues that by default PSS are not more environmentally benign compared to other conventional systems. As such, the exemplification of how LCA studies can support the definition and refinement of circular business models focused on product/service-systems, at early development stages within an industrial context is needed. Thus, this paper contributes to the existing knowledge by exploring how LCA can support the development of a PSS for clothing supplied to the British Special Forces (BSF), and further quantification of the environmental potentials of this offering to the MoD.

\section{Literature Background}

In circular economy literature presents several classifications or archetypes of circular economy business models (CEBMs). For example, Ludeke-Freund et al. identified 26 archetypes of CEBMs with different purposes, such as either as a mean to redefine value creation, or to offer clarity of terms [23]. Bakker et al. take a product design perspective to classify different CEBMs [24]. Lewandowski look at CEBMs from a practical method [25]. Lacy and Rutqvist and Bocken et al. do their classification from a value perspective, where the latter introduces its classification according to strategies to slow resource use or close resource use [12,26]. The Ellen MacArthur Foundation looks at financial incentives [27] and Tukker looks at it from a service provision perspective [28]. More recently, Urbinati et al. did a 
taxonomy based on the degree of adoption of circularity along the value proposition and the value network [29]. These are just to mention a few taxonomies in the literature. For the purpose of this paper, we will follow the classification of Moreno et al. where CEBMs are classified according to the value gained from slowing or closing resource use and the primary source of revenue gained in doing so [30]. This classification is the following:

- Circular supplies: A business model based on industrial symbiosis in which the residual outputs from one process can be used as feedstock for another process.

- Resource value: A business model based on recovering the resource value of materials and resources to be used in new forms of value.

- Product life extension: Those business models that are based on extending the working life of a product.

- Extending product value: Those business models based on offering product access and retaining ownership to internalise benefits of circular resource productivity mainly through a product-oriented PSS (i.e., products are sold to users, but additional services are added such as insurance or maintenance) or a use oriented PSS (i.e., products are leased or rented to the user).

- Sharing platforms: Those business models that enable increased utilisation rates of products by making possible shared use/access/ownership through a peer-to-peer model (or a result-oriented PSS).

\subsection{Extending Product Value as One of the Potential CEBMs through a Use-Oriented PSS}

Product/service-systems (PSS) are often seen as one of the key enablers for a Circular Economy [17], due to their potential to decouple value creation from resource consumption [22,31]. Several definitions exist for PSS [16], which is often defined as a combination of products and services capable of fulfilling user needs and competitiveness in the market through new business models.

It is widely recognized that PSS has the potential to enable enhanced environmental performance and circularity by means of a number of strategies [32-36], such as:

- dematerialize value delivery (e.g., by means of virtual platforms);

- $\quad$ enhance product utilization and capacity (e.g., by means of sharing/pooling models);

- $\quad$ enhance product efficiency during the use phase (e.g., by means of predictive maintenance services and/or consultancy/advice for efficient product use);

- $\quad$ enhance product effectiveness (e.g., by focusing the value proposition on value delivery);

- extend the product lifetime (e.g., through predictive maintenance, updates and repair)

- optimize take-back and end-of-use strategies (e.g., by keeping ownership of the products in use-oriented and result-oriented PSS models);

- enable the implementation of circular strategies to close the material loop (such as remanufacturing, refurbishment, reuse and recycling).

Nevertheless, it is important to notice that PSS is not intrinsically more sustainable, nor circular by definition [37-40] — there are actually a number of examples that show that PSS can lead to rebound effects and adverse environmental consequences [40].

In order to support the evaluation of the environmental performance of PSS solutions, and on the basis of existing challenges for the evaluation, Kjær developed a number of guidelines that can serve as a support when designing and evaluation PSS [41]. Pieroni et al. proposed a number of sustainability qualifying criteria for evaluating circular business models [42], and Kravchenko et al. developed a database with sustainability performance indicators that can be used to measure circular initiatives and business models [43]. The opportunity relies in evaluating the environmental performance of PSS initiatives as early as possible in the development process, so as to support the development of more sustainable solutions through fact-based decision-making processes. 


\subsection{PSS Models in the Textile Industry}

A New Textile Economy Report calls for action to increase the average number of times clothes are worn as the most direct way to capture value and design out waste and pollution in the textile industry. Armstrong et al. propose PSS based on clothing take-back, swaps and leasing services that include repairs, redesign and consultancy as a way forward. Shifting the mindset of selling access to clothes could help to design and produce garments of better quality, shift the perception of clothing from being disposable item to be a durable product [44]. Therefore, in the case of Armadillo Merino ${ }^{\circledR}$, implementing a PSS make sense, as quality is in the heart of their garments' design. Armstrong et al.'s research found some negative perceptions between the public about PSS for apparel [21]. This includes lack of trust in the service provider and perceived barriers to ease of use, lack of accessibility and other technical requirements (e.g., due to repair and maintenance of the clothes). Therefore, PSS for brands and retailers might be more difficult to implement, and they would prefer other types of CEMBs such as take-back schemes rather than leasing services [45]. Therefore, the Ellen MacArthur Foundation (EMF) report calls to start this type of service alongside public procurement to lead the way for the private sector to follow.

\section{Materials and Methods}

The development and quantification of the environmental performance of a PSS business model was performed in the context of a case study [46]. The chosen case study is explained in further detail below.

\subsection{The Armadillo Merino ${ }^{\circledR}$ Case Study}

The Ministry of Wool trading as Armadillo Merino ${ }^{\circledR}$ (AM) is a UK based company that produces Merino wool next-to-skin garments. Currently, the company is working with the MoD's "Trials and Evaluation Programme" to test AM products and AM as a garment supplier to the British Special Forces (BSF). AM has found that the cost of market entry is a barrier as their products are $30 \%$ more expensive than the synthetic (e.g., polyester or nylon) next-to-skin garments that are currently used by the MoD. However, there is considerable interest by AM to provide a solution to the MoD, which could prove competitive to the synthetic garments provided by sportswear clothing companies. As such, providing a CfA based on a PSS business model could be the solution for AM. Providing a PSS could help AM to re-position Merino wool garments as a cost-effective solution that provides performance and user comfort, to disprove the perception of wool being expensive and uncomfortable [47]. With fine wools and modern manufacturing techniques, Merino wool proves to have unique properties, which synthetic fabrics do not have. These include anti-static properties, UV protective features, reduction of odour and improved comfort $[48,49]$. In this paper, these properties are referred to as protection, performance and comfort to the end user. In addition, providing a PSS business to the MoD could contribute to a circular economy as AM would take the responsibility of supplying the garments to the $\mathrm{MoD}$, as well as the responsibility of repurposing (repair and maintenance) and reissuing garments for re-use, thereby extending their lifetime. In addition, AM will take responsibility of garments at end-of-life with a range of options such as the recycling of garments into new merino t-shirts or into other army applications (blankets, sound buffering, compression pads, etc.) when the garments are beyond repair. This could help the MoD to reduce inventory management costs, as AM will be supplying garments on demand.

\subsection{Research Scope and Objectives}

To understand and demonstrate the environmental potentials of providing a PSS of Merino wool t-shirts to the BSF within this case study, three objectives were established:

1. Understand the current supply chain of the MoD's Special Forces' wearing kit including Merino wool t-shirts. 
2. Develop a PSS business model based on the knowledge acquired from the present supply system to provide an alternative business solution for the MoD.

3. Quantify the environmental potentials of the developed PSS by means of the LCA methodology.

To meet these objectives, we followed Kjaer's [41] suggestions when applying LCA methodology to assess the environmental performance of a PSS. Kjaer [22,40] suggests three relevant scopes being:

1. PSS optimisation - evaluating options within the PSS itself.

2. PSS comparison - comparing a PSS with an alternative, which in most cases is a conventional business model.

3. PSS consequences-modelling the actual contextual changes caused by the PSS.

Since our study intends to develop an alternative model to the current system, the evaluation was done following a "PSS comparison scope" (see References [22,40] for a detailed differentiation between the three scopes). The PSS comparison was done between the current system (i.e., the reference system) and the suggested PSS. Following Kjaer's suggestions [41], we had first to identify a reference system (being Objective 1 of this study), to then define a functional unit and set the system boundaries that applied to the reference system and the developed PSS.

The following steps (Figure 1) were conducted to achieve the former, and fulfil the three objectives:

- $\quad$ Step 1: Two workshops were run to gather the sufficient data in order to define the reference system and design the new PSS alternative (Objectives 1,2).

- Step 2: Quantify the environmental potentials through a screening level life cycle assessment (LCA) (Objective 3). In order to quantify the environmental potentials, we determined the functional unit and the systems boundaries as suggested by References $[22,40]$.

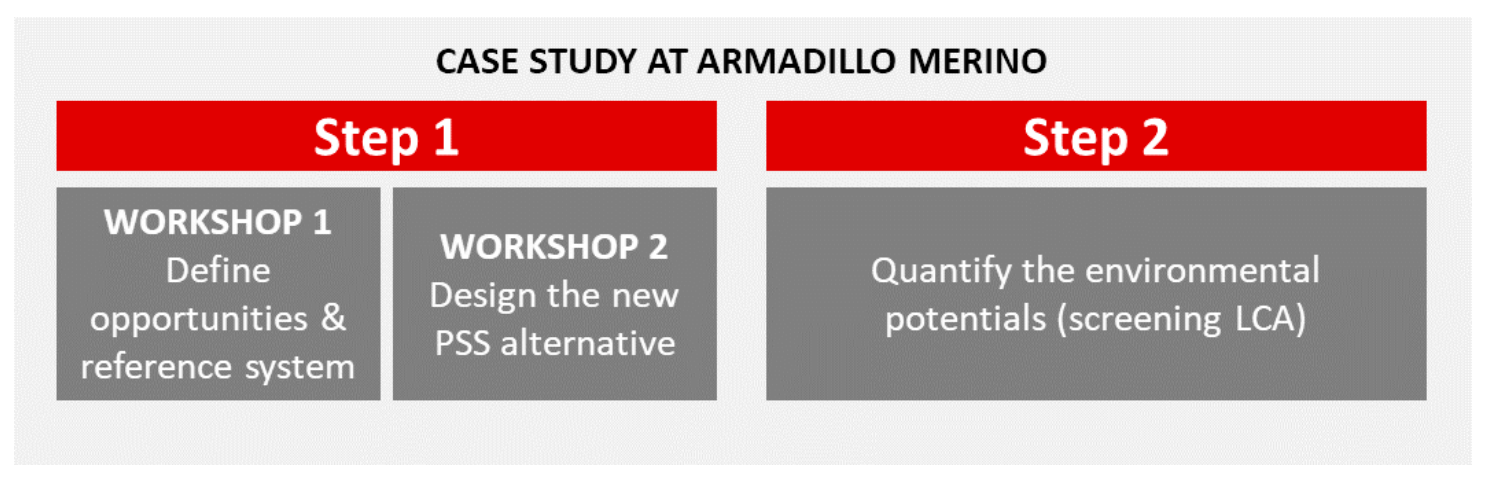

Figure 1. Overview of key steps and workshops carried out during the case study.

\subsubsection{Step 1-Workshops}

Workshop 1: Defining the Reference System

To define the reference system (details are presented in the "reference system and PSS business model" section below), four experts were invited to the initial workshop. These included a Procurement Lead for Capability Development (MoD), a MoD Procurement Expert (Former UK Air Forces), a weaving textile expert (Business Consultant) and a service provider expert (Business Consultant). With these experts, we explored how the MoD's clothing procurement system works. The aim of the workshop was twofold: To explore further opportunities to shift from the current linear model to a suitable PSS, to then define the reference system on how garments are provided to the MoD. The opportunities were delved with a facilitated round table discussion based on the following themes: quality and properties of the Armadillo Garments, gains for the MoD and gains for Armadillo Merino, and how to better capitalise from the current system on how the MoD operates. The opportunities 
found are described in Section 4. Once the opportunities were defined, the experts helped to define the reference system through a system map (i.e., a design tool to define the different elements on a system, its stakeholders, its processes and interactions http://www.servicedesigntools.org/tools/28) exercise where the steps of how garments are distributed to the MoD was depicted.

\section{Workshop 2: Designing a PSS Circular Business Model}

The assessment of opportunities was presented to a panel of experts to further refine the design of the PSS business model during a second workshop. Attendees of the second workshop included: an expert on circular economy (Ellen MacArthur Foundation), an expert on sustainable business models (The Sustainable Business Group), an expert on PSS design (Cranfield University), a supply chain consultant (Re-Think Solutions), a Procurement Lead for Capability Development (MoD) and a MoD procurement expert (Former UK Air Forces). In this second workshop, a system map exercise was again used to design the PSS alternative model.

\subsubsection{Step 2-Quantifying the Environmental Potentials}

To achieve Objective 3 of this study, an LCA was conducted to quantify and compare the environmental performance polyester/nylon t-shirts offered through a transactional business model (i.e., the reference system) with Merino wool t-shirts offered through a PSS business model to the BSF.

It should be emphasised that this assessment only considers climate change impacts (CCIPs), whereas other environmental impacts are likely to be equally important as measures of environmental sustainability for textile products, including water use, land use related impacts, eutrophication, toxicity related impacts and acidification [50]. The focus on CCIPs was chosen, as this environmental impact category is an established sustainability measure for the MoD and for the Merino wool sector in general. CCIPs has been one of the most widely adopted environmental impact categories in studies assessing the environmental impacts from garments produced from wool [50,51], however as established below, a number of present studies do not fully account for all relevant greenhouse gasses contributing to wool production, which is why this environmental impact category is relevant to further exploration.

To determine the main activities and the associated CCIPs that differ across the two product systems, the study was carried out as a prospective screening LCA, which implies that simplifications and assumptions are accepted. The scope of a screening LCA was well suited in terms of deciding whether to pursue the proposed PSS business model and most importantly as a basis to investigate if/how a PSS business model may influence the environmental impacts performance of textile products.

In relation to garments produced from wool, these are by some perceived as more environmentally sustainable, e.g., in terms of CCIPs, compared to garments produced from man-made fibres such as polyester and nylon [52]. Wool fibres are of natural origin and are biodegradable, whereas polyester fibres are produced from non-renewable resources (here in the form of crude oil) with proven contributions to climate change. However, the emissions of enteric methane $\left(\mathrm{CH}_{4}\right)$ from the sheep digestion system and nitrous oxide $\left(\mathrm{N}_{2} \mathrm{O}\right)$ from the breakdown of sheep manure have not by default been accounted for as contributions to the climate change impact category for wool production [51-53]. Discounting the gaseous emissions from sheep production is likely to cause underestimation of the CCIPs from wool production, since $\mathrm{CH}_{4}$ is a greenhouse gas (GHG) with a global warming potential (GWP) approximately 21 times more effective than $\mathrm{CO}_{2}$ and $\mathrm{N}_{2} \mathrm{O}$ is approximately 310 times more effective [54].

\section{Results}

\subsection{Step 1: Workshop 1 Results-Define Opportunities and Reference System}

The identified opportunities to shift to a PSS business model at Armadillo can be described as:

- To capitalise on the properties of Merino wool t-shirts in terms of providing protection, performance and comfort as an alternative to polyester/nylon t-shirts. 
- To capitalise on a rolling CfA contract, which is considered on the MoD's expenditure annual budgets.

- To supply garments to a supply pool supporting the BSF might prove easier than to supply to regular operations as all specialist equipment for each tour is planned and managed by a special MoD supply pool.

- To focus on the BSF supply pool mechanisms where specialist equipment normally is returned to the pool after a mission for refurbishment and restocking.

- To use the current MoD's supply system. Currently, the supply of garments is managed by the quartermasters and through a requisition order.

- A tour lasts six months and five synthetic t-shirts are issued for each soldier for each tour. It was agreed by the workshop participants that only three Merino wool $t$-shirts would be required per six months in case the $\mathrm{t}$-shirts were offered through a PSS.

- To capitalise on using the current MoD's freight system and North Atlantic Treaty Organization (NATO) stocking numbers (NSN) tracking system to ensure that the garments are returned to the supply pool after each tour.

The Reference System:

The data gathered during the first workshop were used to define the reference system based on the current system (see Section 4.3 below). As the researchers did not have access to current MoD data, assumptions were made according to the participant's knowledge and expertise and, where possible, assumptions were rectified with secondary data from databases, peer-review publications, reports and personal communication with washing machine manufacturers.

Based on the data gathering, it was established that the $t$-shirts in the reference system are produced in China (CN) from $50 \%$ polyester and $50 \%$ nylon. Compared to other fibres, garments produced from synthetics such as polyester more easily take on and persist odour $[49,55]$ and each $t$-shirt is washed after one day of use. As each soldier is equipped with five $t$-shirts per six-month tour, each $t$-shirt is laundered (washed and dried) 36 times per tour. It is assumed that half the $t$-shirts are incinerated in open fire pits prior to repatriation, whereas the other half is brought back to the UK and landfilled.

For the proposed PSS business model, AM provided the needed product life cycle system data. The t-shirts are produced in CN from 100\% Merino wool that is sourced from Merino sheep farms in New Zealand (NZ). As wool garments are less susceptible to odour compared to polyester [56,57], the $\mathrm{t}$-shirts are worn for three days between washes. As such, it is implied that each $\mathrm{t}$-shirt must be washed 20 times per operation and provided the system of reuse and refurbishment each Merino t-shirt will have a lifetime of four tours of six-month duration, i.e., each t-shirt is expected to have a service-life of two years.

As AM retains ownership of the Merino t-shirts they have the option to plan for end-of-life (EoL) strategies, and the planned tracking system based on the NSN number, is expected to ensure a high collection rate (95\%) of EoL t-shirts. AM has not yet decided on a specific EoL strategy, and the present assessment of the PSS also explores closed loop recycling (CLR) where t-shirts are recycled into new Merino t-shirts, as opposed to open loop recycling (OLR) where EoL t-shirts are recycled into new wool applications. Among other aspects the potential (GHG) credits associated with recycling of wool is determined by what is being substituted [58] and since the substituted material for OLR is unspecified, the credits will be based on a CLR scenario, where the recycled Merino t-shirts are expected to substitute raw wool production. The feasibility of using reclaimed fibres for secondary yarn production is addressed in the following sections.

Several barriers apply to CLR of textiles into new woven products, including material composition (mixed fibres, buttons, zippers etc.), differing fibre lengths and colours, impurities etc. These material variations mainly apply to post-consumer textile waste, i.e., textiles discarded by consumers, whereas pre-consumer textile waste such as cut-offs from garment production usually are more homogeneous in terms of purity, fibre length etc. [59-61]. The expected EoL potential of Merino t-shirts fall under the 
former category, however, in contrast to traditional post-consumer textile waste streams the t-shirts are expected to exhibit a relatively high homogeneity and hence a high potential for CLR. This potential is due to the fact that the garments are produced from pure natural materials, and the waste fraction will therefore be homogenous both in terms of materials and colour. In addition, the $t$-shirts are expected to be laundered and are hence clean upon repatriation. Finally, the PSS tracking system ensures a high collection rate, which allows for production planning. To retain the durability of the Merino $t$-shirts AM has estimated that the content of recycled wool in new $\mathrm{t}$-shirts should not exceed $30 \%$ and $\mathrm{t}$-shirts should only be recycled once. To ensure singular recycling, the tracking system could be expanded to contain "historical" information on the fibre content of each t-shirt. The remaining t-shirt fraction is expected to enter into an OLR system, e.g., production of blankets, sound buffering, compression pads or felted products.

According to References $[59,61]$ mechanical methods for converting textile products to fibres have existed since the Industrial Revolution, and today it is still economically feasible to use reclaimed fibres for secondary yarn production. Recycled materials cannot necessarily be assumed to displace raw material production 1:1. To achieve net environmental benefits the environmental impact from all processes related to recycling including losses must be less than the avoided impact from raw material production [58].

As the proposed PSS is yet to be implemented the quantity of t-shirts suitable for CLR can only be estimated. It is likely that the soldiers are exposed to harsh conditions that will damage the t-shirts during certain field operations, which may decrease the quality of the textile waste fraction and thereby the quantity of $\mathrm{t}$-shirts suitable for CLR. Based on the above considerations it was decided to make a conservative estimate of the CLR recycling potential of the collected textile fraction. In the product system modelling it was estimated that $30 \%$ of the collected, used $\mathrm{t}$-shirts would displace the production of raw wool and the PSS was not credited for the remaining $70 \%$ of the $t$-shirts as the exact substituted materials could not be established. Although it was expected that the remaining $70 \%$ would enter into a CLR system with the potential to displace other materials, the PSS was not allocated credits for this remaining fraction. Rather, the potential GHG credits were assumed to counterbalance the GHG emissions associated with losses, recovery processes, transport etc. from CLR recycling of wool into new Merino t-shirts.

The characteristics of the two product systems are listed in Table 1. To perform a comparative assessment of the CCIPs, a functional unit was defined. The desired functionality of the t-shirts is to provide the soldiers with neutral-coloured, short-sleeved base layer $t$-shirts that can be worn underneath the uniform, and the functional unit for the assessment was therefore defined as: "The provision of t-shirts for one soldier during six months in the field".

Table 1. Characteristics of the two systems.

\begin{tabular}{ccc}
\hline Characteristics & Reference System & PSS \\
\hline Material & $50 \%$ polyester, $50 \%$ nylon & $100 \%$ merino wool \\
\hline T-shirt weight & $0.157 \mathrm{~kg}$ & $0.157 \mathrm{~kg}$ \\
\hline $\begin{array}{c}\text { Number of t-shirts (per six months tour) } \\
\text { Laundering (number of machines washes } \\
\text { per six months use periods) }\end{array}$ & 5 & 3 \\
\hline Collection rate for CLR & 36 & 20 \\
\hline Open burning abroad & - & $95 \%$ \\
\hline Landfill in the UK & $50 \%$ & - \\
\hline Substitution of raw material from CLR & $50 \%$ & $30 \%$ \\
\hline Steam wash (kWh per wash) & - & 0.05 \\
\hline Regular wash (kWh per wash) & 0.21 & 0.05 \\
\hline
\end{tabular}




\subsection{Step 1: Workshop 2 Results_Designing a PSS Circular Business Model}

The proposed PSS model was based on the concept that AM owns and manages the Special Forces supply pool for next-to-skin garments and leases these garments directly to the MoD. The idea was that the PSS solution is intended to provide real-time inventory management of high quality products that will provide a safer, more comfortable user experience for MoD personnel by providing them with wool next to skin t-shirts (for the scale of the study only short sleeve t-shirts in light olive and/or coyote brown are considered) that require maintenance; as an alternative to polyester/nylon t-shirts. Figure 2 shows the AM areas of responsibility, including the logistics associated with reuse and redistribution, refurbishment and remanufacture.

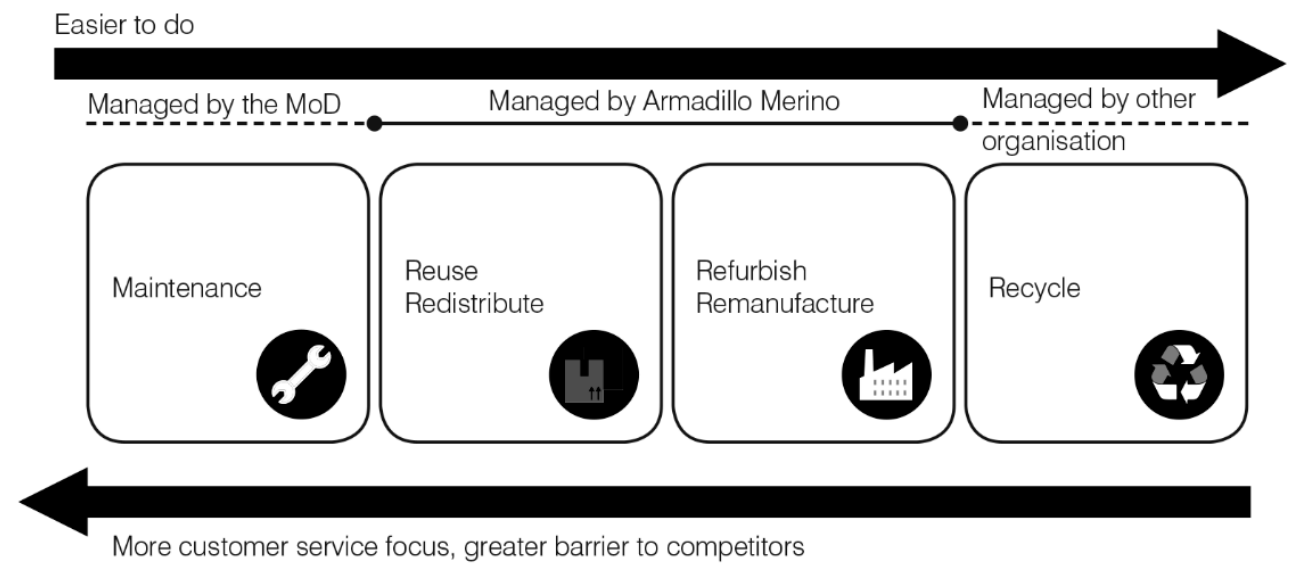

Figure 2. Area of responsibility of Armadillo Merino ${ }^{\circledR}$.

\subsection{Step 2: Assessing the Environmental Potentials_Process Mapping, Data Gathering and Impact Assessment}

The screening LCA presented here took a cradle-to-cradle approach covering the main processes from raw material to recycling/EoL. In this inventory phase of the LCA, the system boundaries (included and omitted processes) were mapped out and inventory data gathered for the life cycles of both product systems. In the impact assessment impact potentials were calculated for GHG emissions and quantified over the entire life cycle, building the foundation for quantification of the climate change impact potential of the system per functional unit.

System Constellation for the Reference System:

The assessment of the reference system was based on five main life cycle stages (for illustration, see Figure 3):

- $\quad$ Raw material: production of synthetic fibres (a blend of polyethylene and nylon fibres) at factories in CN.

- T-shirt production: conversion of fibres to yarn, from yarn to fabric and fabric to t-shirts in CN.

- Use stage: laundering process (machine washing) at operations in the field.

- Transport: ship transport of manufactured t-shirts from CN to the UK.

- EoL: open pit burning of EoL t-shirts prior to repatriation from operations abroad.

System Constellation for the PSS:

The assessment of the PSS was based on the following five life cycle stages (for illustration see Figure 4):

- Raw material: production of greasy wool fibres at NZ Merino sheep farms with sheep meat as by-product. The main activity is shearing; the process by which the woollen fleece is cut off the sheep. 
- Pre-treatment: scouring of greasy wool at facilities in CN. The main output is dry, clean fibres (wool tops) for further processing.

- T-shirt production: conversion of fibres to yarn, from yarn to fabric and fabric to t-shirts in $\mathrm{CN}$.

- Use stage: Laundering process (machine washing) at operations abroad.

- Transport: Ship transport from NZ to the UK.

- EoL: CLR of EoL Merino t-shirts (30\%). The remainder (70\%) is expected counterbalance the GHG emissions associated with losses, recovery processes, transport etc. from CLR recycling of wool into new Merino t-shirts.

Inventory data were mainly obtained from the Ecoinvent database version 3 [62] and secondly from a publication by the Waste and Resources Action Programme (WRAP) in UK [63]. The data from WRAP are partly based on the Ecoinvent database version 2; on a publication on environmental assessment of textiles by the Danish Environmental Protection Agency (EPA) [64] and on supplementary work by Environmental Resources Management (ERM) that was commissioned to conduct the WRAP publication [63]. Data on machine washing were acquired from Miele and Nortec (through interviews), and finally, a report from the U.S. EPA provided data on open pit burning of polyester.

Inventory data obtained from the Ecoinvent database were used to model the product system using Sima Pro 8.1.1 [65] and by applying the ReCiPe characterisation method for which climate change characterisation factors are based on the guidelines provide by the Intergovernmental Panel on Climate Change (IPCC). The characterisation allowed for conversion of all GHG emissions to the same unit, $\mathrm{CO}_{2}$-equivalents $\left(\mathrm{CO}_{2} \mathrm{e}\right)$. The same characterization method was applied in the WRAP publication [63].

In the flowcharts (Figure 3, Figure 4) the GHG emissions for each life cycle stage were quantified and the associated inventory data sources listed below each stage.
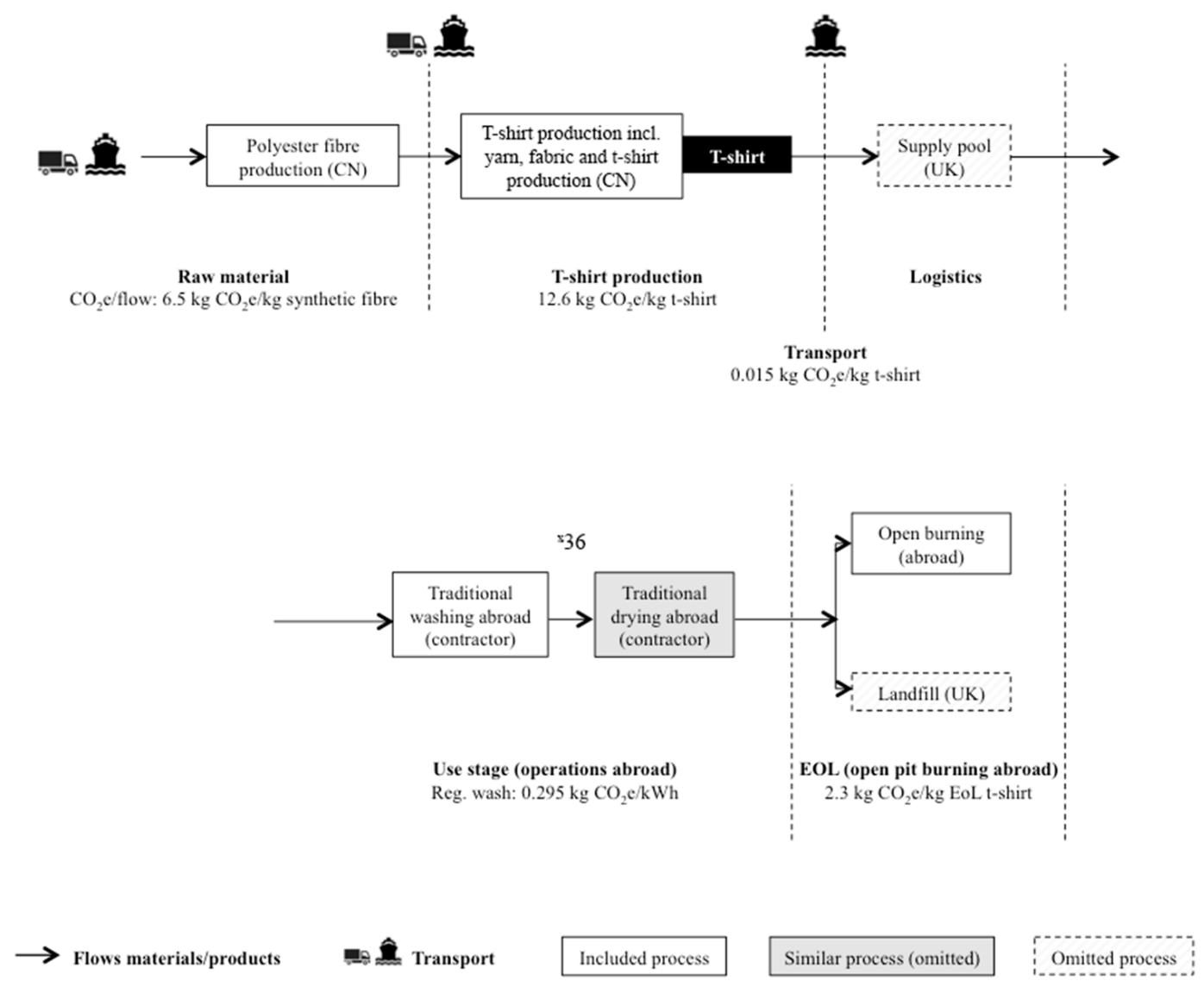

Figure 3. Process mapping and quantified flows with data sources, reference system. 

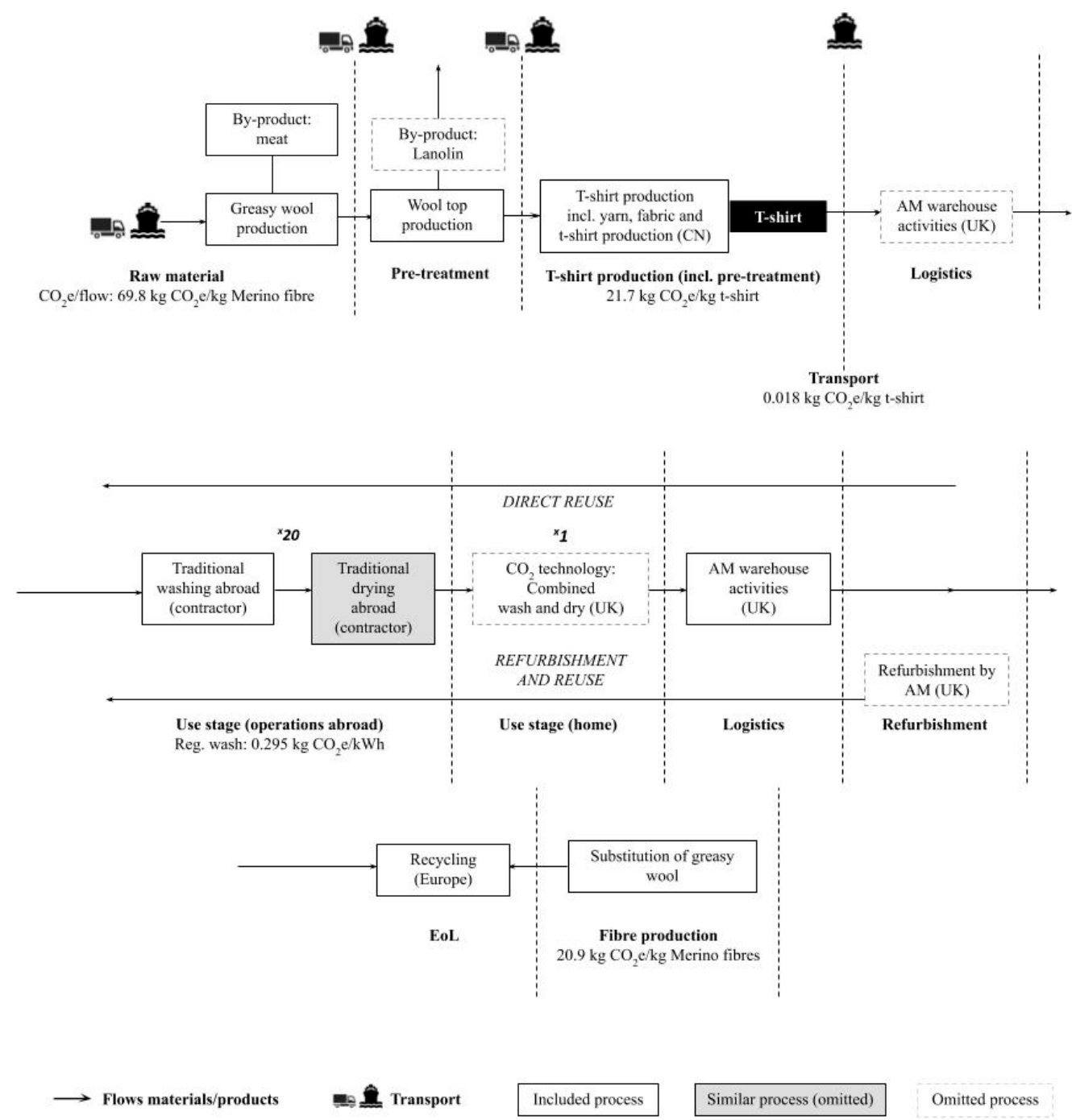

Figure 4. Process mapping and quantified flows with data sources, product/service-system (PSS).

Simplifications and Assumptions:

- Processes that were assessed as comparable for the two systems were not included in the impact assessment.

- Based on the chosen level of detail, only transport processes over longer distances were assessed.

- In the use-stage for both systems, a steam and a regular washing machine were tested. Both machines were modelled as run by diesel generators and an oil boiler was selected for steam generation.

- Logistics (covering only warehouse activities) were omitted due to lack of information on the activities involved.

- In contrast to other impact categories it was assumed that landfilling of synthetic t-shirts is less significant for CCIPs, and hence the life cycle stage EoL landfill (i.e., in UK) was not accounted for.

- Due to a lack of process data, the life cycle stage $t$-shirt production in the PSS was based on similar cotton-based processes. Other literature sources including WRAP applies cotton textile production as a proxy for wool textile production.

- The cleaning activity involved in cotton textile production was regarded as a proxy for wool scouring.

- The main by-product from wool scouring is lanolin, which is used by the cosmetics industry. Due to lack of process data no GHG emissions were allocated to lanolin production. According to 
Reference [50] the recovery of lanolin amounts to approximately $10 \%$ the value of greasy wool and most GHG emissions are thus allocated to the wool.

- The ship transport of wool tops from NZ to CN, and subsequently from $\mathrm{CN}$ to UK was simplified and modelled as direct transport between NZ and UK. The omitted transport distance by ship was not expected to have significant influence on the results.

- Upon each operation, the Merino t-shirts are to be laundered prior to reuse/refurbishment and redistribution. AM is currently considering a combined washing and drying machine based on liquid $\mathrm{CO}_{2}$. The process was omitted, as no data could be obtained and since it is only expected take place once every six months.

- As the PSS is yet to be implemented no quantitative system data were available, nor included in the impact assessment for the reuse, refurbishment and redistribution related processes. The main activities were expected to be associated with low GHG emission activities based on manual labour, including sewing. Some demand for land transport was expected (to and from the dressmaking factories).

To associate the process flows to the functional unit, the characteristics of both systems were finally parameterized and associated to the inventory data for each life cycle.

The Climate Change Impacts:

Figure 5 presents the CCIPs (total and divided into life cycle stages) per functional unit for the reference system and the PSS. The results revealed that the reference system had the highest total CCIPs (16.9 $\mathrm{kg} \mathrm{CO}_{2} \mathrm{e} / \mathrm{FU}$ (Functional Unit)) approximately twice the size of that for the PSS (8.6 $\left.\mathrm{kg} \mathrm{CO}_{2} \mathrm{e} / \mathrm{FU}\right)$.

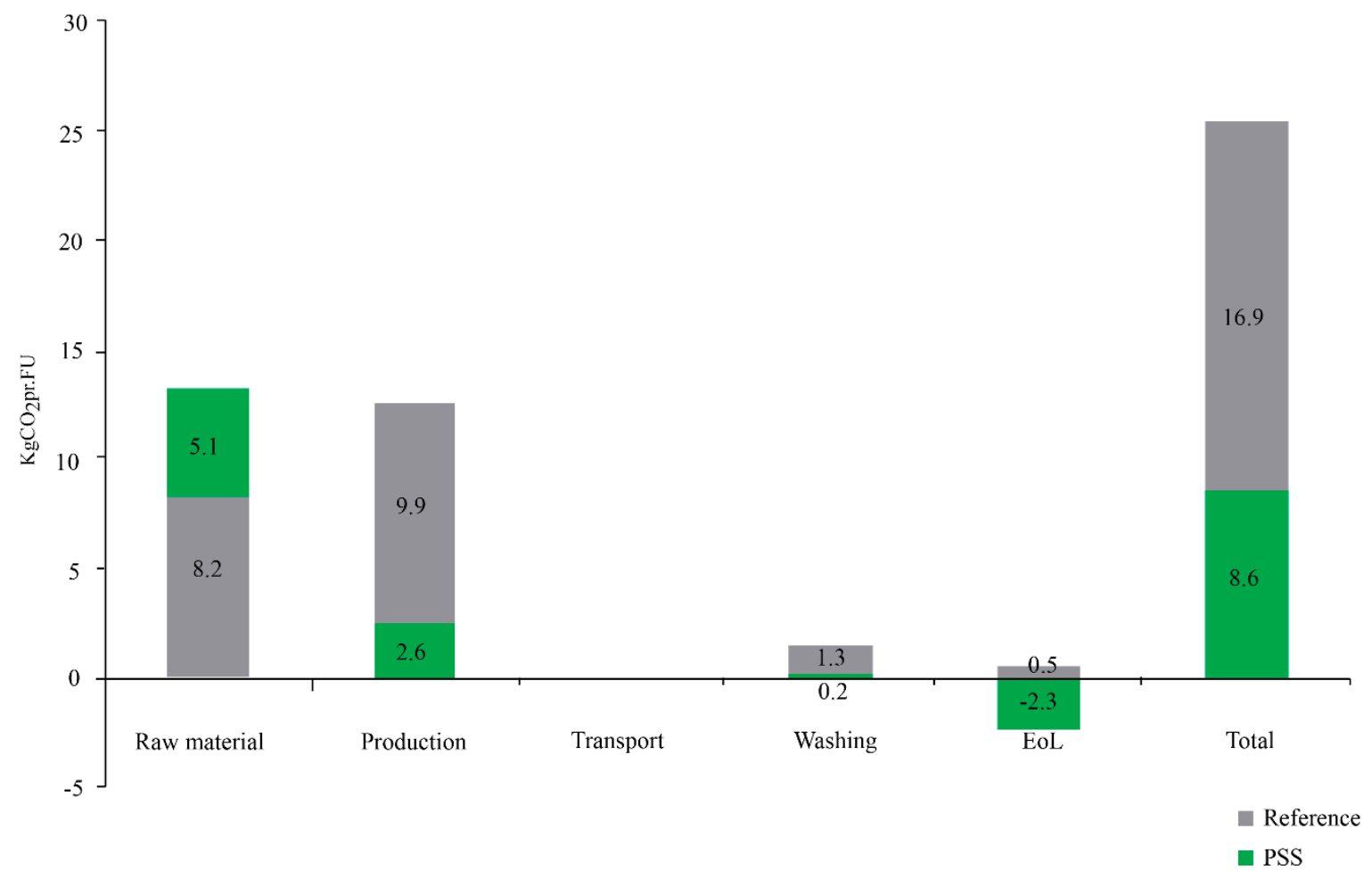

Figure 5. Climate change impacts per functional unit (FU) for the reference system (e.g., synthetic t-shirts) and the PSS (e.g., Merino wool t-shirts).

As can be observed in the figure, the life cycle stages "raw material" and "t-shirt production" contributed the most to GHG emissions. For the PSS, the GHG emissions associated with "raw material production" exceeded the emissions of the reference system by approximately $60 \%$, whereas the CCIPs 
resulting from t-shirt production in the reference system was nearly three times the impacts attributed to the PSS.

The life cycle stages "transport" and "washing" were insignificant to the results. For the PSS-based system GHG credits from recycling at EoL $(-2.3 \mathrm{~kg} \mathrm{CO} 2 \mathrm{e} / \mathrm{FU})$ are of noticeable magnitude to the overall result.

In Figure 6 the CCIPs are presented for one reference t-shirt and one Merino t-shirt respectively. It became evident that once the Merino t-shirt was no longer offered through a PSS business model (or another system ensuring maximum utilization of the wool material) the total GHG emissions could increase to $14.4 \mathrm{~kg} \mathrm{CO} \mathrm{CO}_{2} \mathrm{e}$-shirt and the $\mathrm{t}$-shirt in the reference system thereby becomes preferable in terms of CCIP performance (3.2 $\mathrm{kg} \mathrm{CO} \mathrm{CO}_{2} \mathrm{e}$ t-shirt).

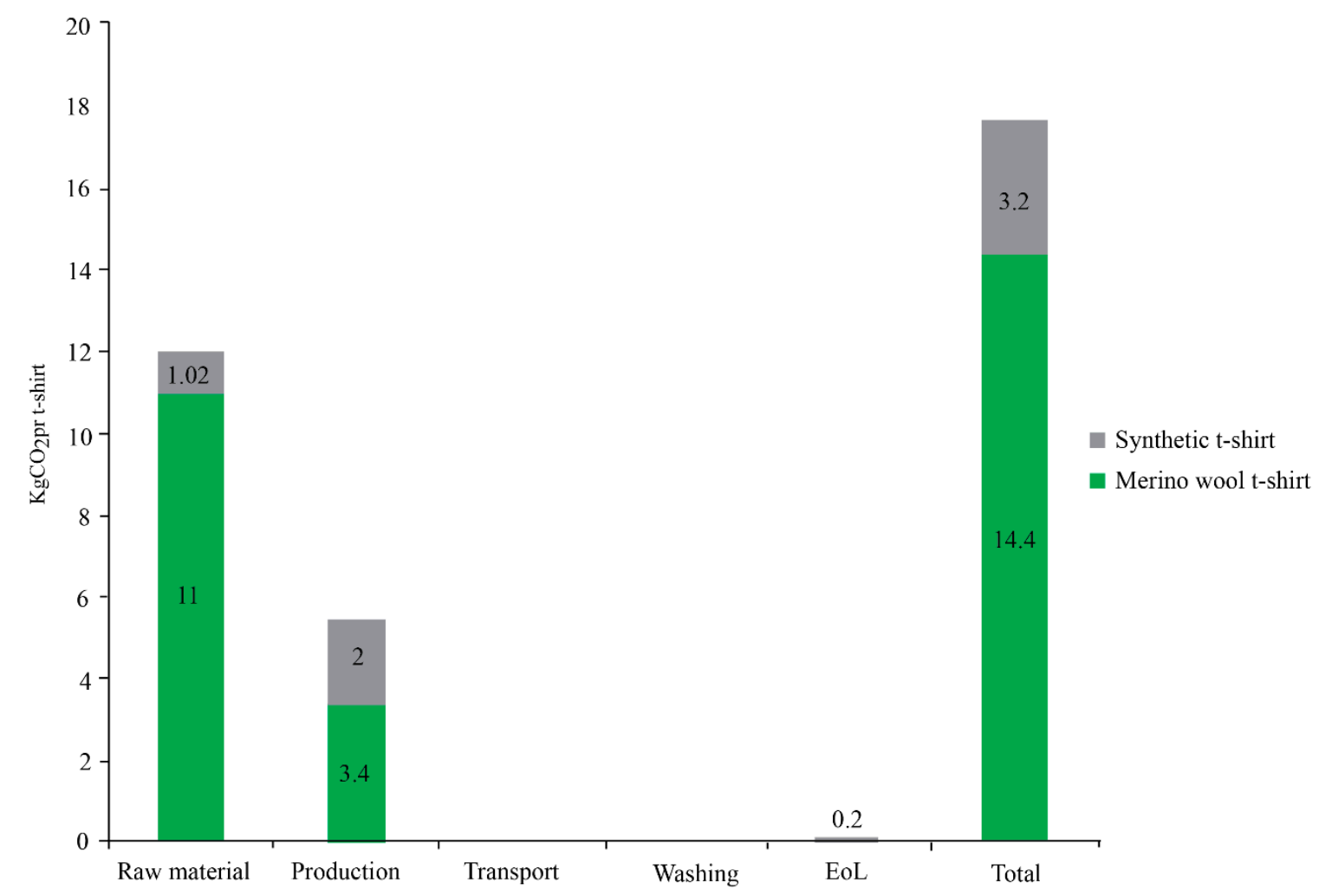

Figure 6. Climate change impacts per t-shirt from the reference system and the PSS.

When the CCIPs were quantified per t-shirt, the significance of the GHG emissions associated with "raw material production" became further pronounced. Relatively speaking the GHG emissions from the production of Merino wool fibres are ten times the magnitude of that of the production of fibres for the reference $t$-shirt, which could be attributed to the fact that the production of wool is related to other GHG emissions than $\mathrm{CO}_{2}$ such as methane $\left(\mathrm{CH}_{4}\right)$ and laughing gas $\left(\mathrm{N}_{2} \mathrm{O}\right)$ having much larger global warming potentials than $\mathrm{CO}_{2}$. From the Ecoinvent database it was derived that approximately $55 \%$ of the GHG emissions from greasy wool production was attributed to $\mathrm{CH}_{4}$ and approximately $30 \%$ was attributed to emissions of $\mathrm{N}_{2} \mathrm{O}$, which illustrates the importance of accounting for all GHG emissions at the Merino sheep farms.

In favour of the reference $t$-shirt, the CCIP pattern for the $t$-shirt production was reversed when measured per $t$-shirt. The GHG emissions were reduced with a factor four for the reference $t$-shirt, whereas the CCIPs increased by 30\% for the Merino t-shirt when calculated per t-shirt.

In conclusion, the results show that in terms of the CCIPs of the Merino $t$-shirts offered through the PSS is preferable compared to the reference $t$-shirts offered through a transactional business model. The PSS business model is the basic pre-condition for the superiority of the Merino t-shirt as the ranking of the results (and products) is reversed when compared per t-shirt. Lastly, "raw material" 
and "t-shirt production" were both irrespective of the functional unit identified as the life cycle stages with the largest impact on the results.

\subsection{Testing the Robustness of the Results}

Often, sensitivity analysis is carried out in LCAs to test system boundaries, allocation approaches, parameter values and characterization methods [66]. In this case, we wanted to test the parameter values given in the PSS model. Therefore, the sensitivity of the product system model was tested applying a sensitivity ratio analysis. When applying a ratio sensitivity analysis, a ratio is calculated to determine the percentage; a given input parameter needs to be changed in order to reverse the ranking of the results [67].

The sensitivity analysis results showed that the number of $t$-shirts allocated to each soldier per six-month tour and the durability of the $\mathrm{t}$-shirts (the number of six-months use periods per $\mathrm{t}$-shirt) were the two most influencing input parameters and in this case significant for the PSS in order to be superior to the reference system when compared on a functional unit basis. In order to test the sensitivity of the results to a change in input parameters sensitivity ratios were calculated for the two parameters. The results are shown in Table 2.

Table 2. The sensitivity of the product system model, i.e., percentages (the sensitivity ratios) by which the input parameters need to be changed in order to reverse the ranking of results.

\begin{tabular}{|c|c|c|c|c|c|c|}
\hline $\begin{array}{l}\text { T-Shirt } \\
\text { System }\end{array}$ & $\begin{array}{c}\text { Input } \\
\text { Parameter } \\
\text { (Most } \\
\text { Influencing) }\end{array}$ & $\begin{array}{c}\text { Input } \\
\text { Parameter } \\
\text { (Current } \\
\text { Values) }\end{array}$ & $\begin{array}{l}\text { CCIP } \\
\text { Pr. T-Shirt } \\
\text { System. } \\
\text { (Current } \\
\text { Values) }\end{array}$ & $\begin{array}{c}\text { Input } \\
\text { Parameter } \\
\text { (Reversed } \\
\text { Results) }\end{array}$ & $\begin{array}{l}\text { CCIP } \\
\text { Pr. T-Shirt } \\
\text { System } \\
\text { (Reversed } \\
\text { Results) }\end{array}$ & $\begin{array}{l}\text { Sensitivity Ratios } \\
\text { (The Percentage that the } \\
\text { Input Parameter Value } \\
\text { Needs to Change in order } \\
\text { to Reverse the Results) }\end{array}$ \\
\hline \multirow[t]{2}{*}{$\begin{array}{l}\text { Reference } \\
\text { system }\end{array}$} & $\begin{array}{l}\text { Number of } \\
\text { t-shirts per } \\
\text { six-months }\end{array}$ & 5 & \multirow[t]{2}{*}{$16.9 \mathrm{~kg} \mathrm{CO}_{2} \mathrm{e}$} & 2.5 & $8.4 \mathrm{~kg} \mathrm{CO}_{2} \mathrm{e}$ & $50 \%$ \\
\hline & $\begin{array}{l}\text { Number of } \\
\text { six-months } \\
\text { use periods }\end{array}$ & 1 & & 2.2 & $8.4 \mathrm{~kg} \mathrm{CO}_{2} \mathrm{e}$ & $120 \%$ \\
\hline \multirow[t]{2}{*}{ PSS } & $\begin{array}{l}\text { Number of } \\
\text { t-shirts per } \\
\text { six-months }\end{array}$ & 3 & \multirow[t]{2}{*}{$8.6 \mathrm{~kg} \mathrm{CO}_{2} \mathrm{e}$} & 6 & $17.2 \mathrm{~kg} \mathrm{CO}_{2} \mathrm{e}$ & $100 \%$ \\
\hline & $\begin{array}{l}\text { Number of } \\
\text { six-months } \\
\text { use periods }\end{array}$ & 4 & & 2 & $17 \mathrm{~kg} \mathrm{CO}_{2} \mathrm{e}$ & $100 \%$ \\
\hline
\end{tabular}

The sensitivity ratio analysis showed that in order to reverse the ranking of the $\mathrm{t}$-shirt systems, the two most influencing input parameters would have to be drastically changed. Either the number of reference $t$-shirts per soldier per six-months would have to be reduced by a factor of two, or the number of Merino t-shirts would have to be doubled. It was not regarded as a viable scenario to reduce the number of reference $t$-shirts per soldier, as this would underestimate the soldiers demand for t-shirts. Conversely, it is more likely that harsh conditions during certain field operations reduce the durability of the Merino t-shirts (and the reference t-shirts), implicating an increase in the demand for t-shirts per six-months tours. As this would apply to both types of $t$-shirts the scenario was not investigated any further.

The sensitivity ratio for the number of six-month use periods for the reference system was calculated to $120 \%$, i.e., in order to reverse the ranking of the results, the number of use periods would have had to increase from 1 to 2.2 tours of six-month duration. Two challenges were identified for prolonging the potential use period of the t-shirts in the reference system. Firstly, synthetic $\mathrm{t}$-shirts more easily take on and persist odour, and although the physical durability of the $t$-shirt would remain beyond the six-month tour, the $t$-shirts are perceived obsolete due to odour (i.e., the reference $t$-shirts are discarded due to aesthetical reasons not technical). Secondly, there is no system for take back and reuse of synthetic $t$-shirts; hence, it is not likely that a prolonged lifetime would decrease the input of 
$\mathrm{t}$-shirts to the MoD supply pools for operations abroad. If the soldiers choose to bring back $\mathrm{t}$-shirts rather than having these burned in open pits, the t-shirts are most likely to fall out of the "official" system. The soldiers may use the $t$-shirts off-duty, which could substitute the purchase of new $t$-shirts for private use and thereby have the potential to reduce the total amount of $t$-shirts produced globally. However, such an assessment is considered highly uncertain, representative for a minority of the $\mathrm{t}$-shirts, and beyond the scope of the present study.

The sensitivity analysis showed that the number of use periods for the Merino t-shirts needed to be halved from four to two in order to reverse the ranking of the results. The exact fraction of Merino $\mathrm{t}$-shirts suitable for direct reuse and/or refurbishment followed by reuse could only be established once the system had been implemented.

\subsection{Recommendations}

The impact assessment showed that the CCIPs from the life cycle of one Merino wool t-shirt exceeded the CCIPs from the reference $t$-shirt with a factor of 3.5. Once the Merino wool $t$-shirts were offered through a PSS business model, the results were reversed in favour of the Merino t-shirt offered via the PSS thus had CCIPs half the magnitude of CCIP of the reference system per functional unit. This entails, that in order for the Merino wool t-shirt to result in fewer GHG emissions than the reference $\mathrm{t}$-shirt, it is vital that PSS strategies are implemented and followed.

The most important PSS strategies were to ensure that the Merino $t$-shirts could be used for four tours of six-month duration and/or the number of t-shirts per soldier per tour was retained, due to the significantly higher CCIPs from the production of greasy wool compared to the synthetic reference fibres. The enforced superiority of the Merino t-shirts could be through the PSS including the tracking system and by establishing an efficient, low-emission reuse and refurbishment system that allowed for realisation of the expected lifetime. In summary, the Merino wool t-shirts from the PSS entail superior CCIP performance compared to the reference system.

\section{Discussion}

This section discusses learning that should be considered through the design process of PSS to minimise or eliminate environmental impacts. The discussion focuses on comparing this quantitative study to a qualitative study attempting to understand environmental impacts from the apparel and textile industry from a waste perspective. In addition, the discussion focuses on a number of challenges that Kjaer et al. [22,40] identified when using LCA to evaluate the environmental performance of PSS. By conducting this case study, we saw a significant contribution of quantifying environmental potential for PSS business models when justifying the transition to a circular economy. However, when adopting LCA methodology for this purpose, the design of the PSS needs to be well thought to overcome some of the identified challenges.

\subsection{Environmental Performance of Circular Business Models in the Apparel and Textile Industry}

Kjaer et al. [22,40] acknowledged the limited number of case studies that use LCA as a methodology to assess the environmental performance of PSS. A study conducted by Corvellec and Stal [45], attempts to evidence the environmental impacts that PSS could have in the apparel and textile industry through a qualitative approach of waste impacts in PSS models in Nordic apparel brands. In contrast, this study demonstrated that LCA is a suitable method to evaluate the climate change impact potentials of a new PSS model, taking as example Merino wool t-shirts offered to the MoD. This is due to the fact that an LCA methodology account for all the relevant life cycle stages that contribute to environmental impacts. Despite that both studies had different focuses (i.e., Corvellec and Stal [45] focused on a business to consumer PSS and the waste impacts caused by the PSS itself. Our study focused on a business to business or public procurement PSS and the $\mathrm{CO}_{2} \mathrm{e}$ impact reduction caused by the PSS itself). There is common learning that could be considered for the future design of PSS as an alternative CEBM. 
In Corvellec and Stal's [45] research, they found out that repair systems allow the active life of garments to be prolonged delaying customers to discard their clothes. However, take back systems or rent or lease systems allow customers to avoid the waste responsibility as customers could exchange their old garments for a voucher in the case of take back schemes or return back used garments after the leasing or renting period. Therefore, an unintended consequence of the PSS could be to increase levels of consumption without lowering levels of production causing more waste [68].

This study demonstrated that the total impacts on climate change per FU is $17.7 \mathrm{~kg} \mathrm{CO}_{2} \mathrm{e}$ in the reference system and $7.0 \mathrm{~kg} \mathrm{CO} 2 \mathrm{e}$ in the proposed circular PSS. This is following the above recommendations with the assumptions that $30 \%$ of the clothes will be returned back to the pool for repurposing (repair and maintenance), the washing temperature will be $30{ }^{\circ} \mathrm{C}$, and that the virgin material substitution rate would be $30 \%$. If these assumptions and recommendations are followed this means that by reissuing Merino t-shirts, this will extend their lifetime. Product life extension is one of the most valuable circular economy strategies [24]. However, Pieroni [11,42] had argued that to capitalise on the benefits of circular business models, their environmental potentials need to be quantified. Through this case study it was demonstrated that this can be done. However, there are still some challenges that needed to be overcome.

In the Armadillo case, the environmental potentials depend on the $30 \%$ returned garments to the pool and on having multiple lifecycles of the same garment. However, the sensitivity analysis showed that the lifecycle of the $t$-shirts would be reduced from four six-month tours to two. This result impacted the design of the PSS model, therefore to minimise environmental impacts, the PSS should be thought in terms of how to keep the value of the garments by having the most multiple lifecycles through increased maintenance and repair. In addition, the Corvellec and Stal [45] study showed that thinking beforehand on strategies on how to prolong the active life of garments through avoiding waste is essential. Therefore, both studies showed that thinking on how value is created, delivered and captured whilst at the same time thinking on how material flows are minimised or eliminated in the design stage of the PSS are essential to avoid environmental impacts $[9,68]$.

\subsection{Challenges to be Overcome for a PSS Comparison Study}

As the PSS model is inexistent at the moment, the workshops helped to define both the reference system and the PSS alternative. This is related to the first challenge identified by Kjaer $[22,40]$ in which innovation and novelty could be achieved with a PSS offering. However, this could be also translated into uncertainty relating to the identification of the correct reference system. In this case study, many assumptions were taken, as the researchers could not access data from the MoD. In addition, PSS are often seen as a design strategy, which is another challenge identified by Kjear et al. Since the PSS presented in this case study is still in a design phase, there are no data regarding a successful implementation, and hence assumptions needed to be made. These limitations had an effect on how the system boundary was defined. As such, a scenario approach validated by secondary data was used to define the boundaries of the reference system and PSS, which helped to conduct the presented screening LCA. Once the PSS business model is implemented a second LCA could be conducted in order to validate the initial results.

In addition, the design of the business model could also benefit by taking into account customer requirements, especially as the proposed PSS model would be operating on a regulated market (such as Defence), where the customer (MoD) need to operate following public procurement rules, and it is more difficult for the end user (MoD personnel) to make purchasing decisions [69]. To minimise the impact of the PSS to the current procurement system that the MoD follows, it was suggested that the PSS used the current freight system. This would help to facilitate the delivery of the PSS and possibly the acceptance of the PSS in this type of regulated market. However, a limitation to this study was that the market implications were out of scope, and therefore further study where customer needs and expectations are considered in the design process as the one conducted by Fargnoli et al. [70] could help to refine the proposed PSS design as well as understand if the proposed PSS model could work 
outside a regulated market, as for now the proposed PSS is highly dependent on using the MoD freight for it to work.

This case study acknowledged that a broader perspective of LCA should be applied when assessing the environmental performance of PSS as suggested by Kjaer [22,40]. During the second workshop, different behavioural and contextual aspects were taken into account. As acknowledged by Reference [71], the environmental impacts of a PSS depend to a large extent on user behaviour and on the socio-cultural context in which the PSS is offered. Kjaer [22,40] see these two aspects as further challenges. In addition, the PSS design considered a whole perspective by thinking in multiple life cycles for the Merino T-shirts, by exploring CLR and OLR systems. This is related to another challenge identified by Kjaer [22,40] where extending the products life into multiple cycles is imperative for PSS models. However, whilst these challenges were considered during the design of the PSS, a full assessment of how behavioural elements and different recycling strategies are implemented need to be re-assessed to have a full perspective of possible rebound effects [22].

Through the case study the tangible and intangible elements that a PSS is characterised of was also identified. As such, as suggested by Kjaer [22,40], the functional unit was supplemented with the description of the sub-functions i.e., "The provision of $t$-shirts for one soldier during six months in the field", that were equal between the reference system and the PSS, as well as being broadly defined. The functional unit needs to be the same when testing the PSS, however this could change regarding the effectiveness of the implementation. If the functional unit changes, this clearly will change the presented LCA results.

\section{Conclusions and Future Work}

Through conducting this case study, it is acknowledged that the LCA methodology could be adopted to assess the environmental performance of PSS. However, further guidance on the topic could help to perform this type of analysis to ensure true environmental benefits of these models. An LCA in the PSS design could give an indication of the environmental potentials of the proposed business models. However, further LCA studies should be conducted during the implementation stage to validate the environmental benefits of this business model. A further validation could help to portray the benefits of circular business models within the circular economy discourse. Future work will include a pilot study to implement the PSS. This implementation could revise some of the assumptions made in this study and could give a more detailed assessment of the delivery of a PSS to the military and possibly other public services.

The theoretical contribution of this research is related to the establishment and exemplification of how LCA studies can support the definition and refinement of circular business models focused on product/service-systems, at early development stages. By providing an overview of the potential environmental impacts of a number of different scenarios, practical support is provided to support the decision-making process and drive the development of more circular and sustainable PSS solutions.

Author Contributions: M.M. is the corresponding author of this manuscript. They acquired the funding for this research, contributed to conduct the primary research and to prepare the original draft and revisions of this manuscript. N.M.B. is the primary author of this manuscript. They conducted the life cycle assessment (LCA) for this research and contributed to prepare the original draft of this manuscript. M.B. advised in the LCA application and reviewed the original draft. F.C. contributed to conduct the primary research and reviewed the original draft. L.L.K. contributed in the LCA methodology to assess the environmental performance of the presented product/service system (PSS). D.C.A.P. supervised the LCA methodology to assess the environmental performance of the presented PSS and contributed to prepare the final manuscript for submission and to revise the manuscript according to the reviewer's comments. M.Z.H. advised in the LCA application. T.C.M. advised the LCA methodology to assess the environmental performance of the presented PSS.

Funding: This research was funded by Innovate UK-Project No: 56436-414320, TP No: 13207.

Acknowledgments: The authors express their deep gratitude to Andy Caughey, Managing Director of the Ministry of Wool trading as Armadillo Merino ${ }^{\circledR}$ for his valuable support in this project. In addition, the corresponding author wants to thank the co-authors of this paper, especially to their colleagues in Denmark that provided guidance and completed the screening LCA study for this project. 
Conflicts of Interest: The authors declare no conflict of interest.

\section{References}

1. Gregson, N.; Crang, M.; Fuller, S.; Holmes, H. Interrogating the circular economy: The moral economy of resource recovery in the EU. Econ. Soc. 2015, 44, 218-243. [CrossRef]

2. Bourguignon, D. Closing the Loop New Circular Economy Package. European Parliamentary Research Service. 2016. Available online: http://www.europarl.europa.eu/RegData/etudes/BRIE/2016/573899/EPRS_ BRI\%282016\%29573899_EN.pdf (accessed on 16 October 2019).

3. Go, T.F.; Wahab, D.A. Hishamuddin H Multiple generation life-cycles for product sustainability: The way forward. J. Clean. Prod. 2015, 95, 16-29. [CrossRef]

4. Pieroni, M.P.; McAloone, T.; Pigosso, D.A.C. Business model innovation for circular economy and sustainability: A review of approaches. J. Clean. Prod. 2019, 215, 198-216. [CrossRef]

5. European Commision. An EU Action Plan for the Circular Economy; European Comission: Brussels, Belgium, 2015.

6. Scottish Government, Natural Scotland. Making Things Last: A Circular Economy Strategy for Scotland; Scotish Government: Scotland, UK, 2016.

7. Grandia, J. Finding the missing link: Examining the mediating role of sustainable public procurement behaviour. J. Clean. Prod. 2016, 124, 183-190. [CrossRef]

8. Rodrigues, D.; Erkoyuncu, J.; Starr, A.; Wilding, S.; Dibble, A.; Laity, M. Review of the modelling approaches for availability contracts in the military context. Procedia CIRP 2015, 30, 451-456. [CrossRef]

9. Bocken, N.M.P.; Short, S.W.; Rana, P.; Evans, S. A literature and practice review to develop sustainable business model archetypes. J. Clean. Prod. 2014, 65, 42-56. [CrossRef]

10. Bocken, N.M.P.; Rana, P.; Short, S.W. Value mapping for sustainable business thinking. J. Ind. Prod. Eng. 2015, 32, 88-102. [CrossRef]

11. Pieroni, M.P.P.; McAloone, T.C.; Pigosso, D.C.A. Configuring new business models for circular economy through product-service systems. Sustainability 2019, 11, 3727. [CrossRef]

12. Lacy, P.; Rutqvist, J. Waste to Wealth: Creating Advantage in a Circular Economy; Palgrave Macmillan: London, UK, 2015.

13. Mont, O.; Tukker, A. Product-Service Systems: Reviewing achievements and refining the research agenda. J. Clean. Prod. 2006, 14, 1451-1454. [CrossRef]

14. Mont, O.; Dalhammar, C.; Jacobsson, N. A new business model for baby prams based on leasing and product remanufacturing. J. Clean. Prod. 2006, 14, 1509-1518. [CrossRef]

15. Baines, T.S.; Lightfoot, H.W.; Evans, S.; Neely, A.D.; Greenough, R.; Peppard, J.; Roy, R.; Shehab, E.; Braganza, A.; Tiwari, A.; et al. State-of-the-art in product-service systems. Proc. Inst. Mech. Eng. Part B J. Eng. Manuf. 2007, 221, 1543-1552. [CrossRef]

16. Haase, R.P.; Pigosso, D.C.A.; McAloone, T.C. Product/Service-System Origins and Trajectories: A Systematic Literature Review of PSS Definitions and their Characteristics. Procedia CIRP 2017, 64, 157-162. [CrossRef]

17. Tukker, A. Eight types of product-service system: Eight ways to sustainability? Experiences from SusProNet. Bus. Strategy Environ. 2004, 13, 246-260. [CrossRef]

18. Erkoyuncu, J.A.; Roy, R.; Shehab, E.; Wardle, P. Uncertainty challenges in service cost estimation for product-service systems in the aerospace and defence industries. In Proceedings of the 19th CIRP Design Conference-Competitive Design 2009, Cranfield University, Cranfield, UK, 1-2 April 2009.

19. Hockley, C.J.; Smith, J.C.; Lacey, L.J. Contracting for Availability and Capability in the Defence Environment. In Complex Engineering Service Systems Decision Engineering; Ng, I., Parry, G., Wild, P., McFarlane, D., Tasker, P., Eds.; Springer: London, UK, 2011; pp. 237-256.

20. Datta, P.P.; Roy, R. Operations strategy for the effective delivery of integrated industrial product-service offerings. Int. J. Oper. Prod. Manag. 2011, 31, 579-603. [CrossRef]

21. Armstrong, C.M.; Niinimäki, K.; Kujala, S.; Karell, E.; Lang, C. Sustainable product-service systems for clothing: Exploring consumer perceptions of consumption alternatives in Finland. J. Clean. Prod. 2015, 97, 30-39. [CrossRef]

22. Kjaer, L.L.; Pigosso, D.C.A.; Niero, M.; Bech, N.M.; McAloone, T.C. Product/Service-Systems for a Circular Economy: The Route to Decoupling Economic Growth from Resource Consumption? J. Ind. Ecol. 2019, 23, 22-35. [CrossRef] 
23. Lüdeke-Freund, F.; Gold, S.; Bocken, N.M.P. A Review and Typology of Circular Economy Business Model Patterns. J. Ind. Ecol. 2019, 23, 36-61. [CrossRef]

24. Bakker, C.; Wang, F.; Huisman, J.; den Hollander, M. Products that go round: Exploring product life extension through design. J. Clean. Prod. 2014, 69, 10-16. [CrossRef]

25. Lewandowski, M. Designing the business models for circular economy-towards the conceptual framework. Sustainability 2016, 8, 43. [CrossRef]

26. Bocken, N.M.P.; De Pauw, I.; Bakker, C.; Van Der Grinten, B. Product design and business model strategies for a circular economy. J. Ind. Prod. Eng. 2016, 33, 308-320. [CrossRef]

27. The Ellen MacArthur Foundation. Towards a Circular Economy-Economic and Business Rationale for an Accelerated Transition. 2015. Available online: https://www.ellenmacarthurfoundation.org/assets/downloads/ TCE_Ellen-MacArthur-Foundation_9-Dec-2015.pdf (accessed on 16 October 2019).

28. Tukker, A. Product services for a resource-efficient and circular economy-A review. J. Clean. Prod. 2015, 97, 76-91. [CrossRef]

29. Urbinati, A.; Chiaroni, D.; Chiesa, V. Towards a new taxonomy of circular economy business models. J. Clean. Prod. 2017, 168, 487-498. [CrossRef]

30. Moreno, M.; Rios, C.D.L.; Rowe, Z.; Charnley, F. A conceptual framework for circular design. Sustainability 2016, 8, 937. [CrossRef]

31. Blomsma, F.; Kjaer, L.; Pigosso, D.; McAloone, T.; Lloyd, S. Exploring Circular Strategy CombinationsTowards Understanding the Role of PSS. Procedia CIRP 2018, 69, 752-757. [CrossRef]

32. Wang, P.; Ming, X.; Li, D.; Wu, Z.; Xu, Z.; Song, W. Achieving sustainability through product-service life cycle management. Int. J. Environ. Technol. Manag. 2011, 14, 516-530. [CrossRef]

33. Tukker, A.; Tischner, U. Product-services as a research field: Past, present and future. Reflections from a decade of research. J. Clean. Prod. 2006, 14, 1552-1556. [CrossRef]

34. Komoto, H.; Tomiyama, T.; Nagel, M.; Silvester, S.; Brezet, H. Life Cycle Simulation for Analyzing Product Service Systems. In Proceedings of the 2005 4th International Symposium on Environmentally Conscious Design and Inverse Manufacturing, Tokyo, Japan, 12-14 December 2005; pp. 386-393. [CrossRef]

35. Doualle, B.; Medini, K.; Boucher, X.; Laforest, V. Investigating Sustainability Assessment Methods of Product-service Systems. Procedia CIRP 2015, 30, 161-166. [CrossRef]

36. Kang, M.-J.; Wimmer, R. Product service systems as systemic cures for obese consumption and production. J. Clean. Prod. 2008, 16, 1146-1152. [CrossRef]

37. Pigosso, D.C.A.; McAloone, T.C. Supporting the Development of Environmentally Sustainable PSS by Means of the Ecodesign Maturity Model. Procedia CIRP 2015, 30, 173-178. [CrossRef]

38. Pigosso, D.C.A.; Mcaloone, T.C. Maturity-based approach for the development of environmentally sustainable product/service-systems. CIRP J. Manuf. Sci. Technol. 2016, 15, 33-41. [CrossRef]

39. Bey, N.; McAloone, T.C. From LCA to PSS-Making leaps towards sustainability by applying product/servicesystem thinking in product development. In Proceedings of the 13th CIRP International Conference on Life Cycle Engineering: LCE2006-Towards a Closed Loop Economy, Leuven, Belgium, 31 May-2 June 2006; pp. 571-576.

40. Kjaer, L.L.; Pagoropoulos, A.; Schmidt, J.H.; McAloone, T.C.; Kjær, L.L. Challenges when evaluating Product/Service-Systems through Life Cycle Assessment. J. Clean. Prod. 2016, 120, 95-104. [CrossRef]

41. Kjaer, L.L.; Pigosso, D.C.A.; McAloone, T.C.; Birkved, M. Guidelines for evaluating the environmental performance of Product/Service-Systems through life cycle assessment. J. Clean. Prod. 2018, 190, 666-678. [CrossRef]

42. De Pádua Pieroni, M.; Pigosso, D.C.A.; McAloone, T.C. Sustainable Qualifying Criteria for Designing Circular Business Models. Procedia CIRP 2018, 69, 799-804. [CrossRef]

43. Kravchenko, M.; Pigosso, D.C.; McAloone, T.C. Towards the ex-ante sustainability screening of circular economy initiatives in manufacturing companies: Consolidation of leading sustainability-related performance indicators. J. Clean. Prod. 2019, 241, 118318. [CrossRef]

44. Ellen MacArthur Foundation. Circular Fashion-A New Textiles Economy: Redesigning Fashion's Future. 2017. Available online: https://www.ellenmacarthurfoundation.org/publications/a-new-textiles-economy-redesigningfashions-future (accessed on 16 October 2019).

45. Stål, H.I.; Corvellec, H. A decoupling perspective on circular business model implementation: Illustrations from Swedish apparel. J. Clean. Prod. 2018, 171, 630-643. [CrossRef] 
46. Yin, R.K. Case Study Research—Design and Methods; SAGE Publications: London, UK, 2006.

47. Sneddon, J.N.; Lee, J.A.; Soutar, G.N. Exploring consumer beliefs about wool apparel in the USA and Australia. J. Text. Inst. 2012, 103, 40-47. [CrossRef]

48. Tester, D.; Mcgregor, B.A.; Staynes, L.; Wang, X. Ultrafine wools: Comfort and handle properties for next-to-skin knitwear and manufacturing performance. Text. Res. J. 2015, 85, 1181-1189. [CrossRef]

49. McQueen, R.H.; Keelan, M.; Xu, Y.; Mah, T. In vivo assessment of odour retention in an antimicrobial silver chloride-treated polyester textile. J. Text. Inst. 2013, 104, 108-117. [CrossRef]

50. Henry, B.K.; Russell, S.J.; Ledgard, S.F.; Gollnow, S.; Wiedemann, S.G.; Nebel, B.; Maslen, D.; Swan, P. LCA of wool textiles and clothing. In Handbook of Life Cycle Assessment (LCA) of Textiles and Clothing; Woodhead Publishing: Cambridge, UK, 2015.

51. Henry, B. Understanding the Environmental Impacts of Wool: A Review of Life Cycle Assessment Studies-A Report Prepared for Australian Wool Innovation E International Wool Textile Organisation. 2012. Available online: https://www.iwto.org/sites/default/files/files/iwto_resource/file/Understanding\%20Wool\%20LCA2\% 2020120513.pdf (accessed on 16 October 2019).

52. Barber, A.; Pellow, G. Life Cycle Assessment: New Zealand Merino total energy use. In Proceedings of the 5th Australian Life Cycle Assessment Society (ALCAS) Conference, Melbourne, Australia, 2 November 2006; pp. 22-24.

53. Bevilacqua, M.; Ciarapica, F.E.; Giacchetta, G.; Marchetti, B. A carbon footprint analysis in the textile supply chain. Int. J. Sustain. Eng. 2011, 4, 24-36. [CrossRef]

54. UNFCCC. Global Warming Potentials. 2014. Available online: http://unfccc.int/ghg_data/items/3825.php (accessed on 18 July 2019).

55. Callewaert, C.; De Maeseneire, E.; Kerckhof, F.-M.; Verliefde, A.; Van De Wiele, T.; Boon, N. Microbial odor profile of polyester and cotton clothes after a fitness session. Appl. Environ. Microbiol. 2014, 80, 6611-6619. [CrossRef]

56. McQueen, R.H.; Laing, R.M.; Brooks, H.J.L.; Niven, B.E. Odor Intensity in Apparel Fabrics and the Link with Bacterial Populations. Text. Res. J. 2007, 77, 449-456. [CrossRef]

57. McQueen, R.H.; Laing, R.M.; Delahunty, C.M.; Brooks, H.J.L.; Niven, B.E.; Laing, R. Retention of axillary odour on apparel fabrics. J. Text. Inst. 2008, 99, 515-523. [CrossRef]

58. Zink, T.; Henderson, A.; Geyer, R.; Kuczenski, B. Common Misconceptions about Recycling. J. Ind. Ecol. 2015, 20, 1010-1017. [CrossRef]

59. Payne, A. Open-and closed-loop recycling of textile and apparel products. In Handbook of Life Cycle Assessment (LCA) of Textiles and Clothing; Woodhead Publishing: Cambridge, UK, 2015; pp. 103-123.

60. Muthu, S.S.; Li, Y.; Hu, J.Y.; Ze, L. Carbon footprint reduction in the textile process chain: Recycling of textile materials. Fibers Polym. 2012, 13, 1065-1070. [CrossRef]

61. Gulich, B. Development of products made of reclaimed fibres. In Recycling in Textiles; Woodhead Publishing: Cambridge, UK, 2006; pp. 117-136.

62. Ecoinvent Centre. EcoInvent. 2015. Available online: http://www.ecoinvent.org (accessed on 18 July 2016).

63. Thomas, B.; Fishwick, M.; Joyce, J.; van Santen, A. A Carbon Footprint for UK Clothing and Opportunities for Savings_Final Report. 2012. Available online: http://www.wrap.org.uk/sites/files/wrap/Appendix\%20IV\%20\%20Carbon\%20footprint\%20report.pdf (accessed on 16 October 2019).

64. Larsen, S.E.; Hansen, J.; Knudsen, H.H.; Wenzel, H.; Larsen, H.F.; Kristensen, F.M. EDIPTEX—Environmental Assessment of Textiles. Working Report No. 24. 2007. Available online: https://orbit.dtu.dk/files/7635219/ EDIPTEX.pdf (accessed on 16 October 2019).

65. PRé. Software to Measure and Improve the Impact of Your Product Life Cycle; SIMAPro: Wallington, UK, 2015.

66. Guo, M.; Murphy, R.J. LCA data quality: Sensitivity and uncertainty analysis. Sci. Total Environ. 2012, 435-436, 230-243. [CrossRef]

67. Björklund, A.E. Survey of approaches to improve reliability in LCA. Int. J. Life Cycle Assess. 2002, 7, 64-72. [CrossRef]

68. Niinimäki, K.; Hassi, L. Emerging design strategies in sustainable production and consumption of textiles and clothing. J. Clean. Prod. 2011, 19, 1876-1883. [CrossRef]

69. Haber, N.; Fargnoli, M.; Sakao, T. Integrating QFD for product-service systems with the Kano model and fuzzy AHP. Total Qual. Manag. Bus. Excell. 2018. [CrossRef] 
70. Fargnoli, M.; Haber, N.; Sakao, T. PSS modularisation: A customer-driven integrated approach. Int. J. Prod. Res. 2019, 57, 4061-4077. [CrossRef]

71. Mont, O. Product-Service Systems: Panacea or Myth? IIIEE; Lund University: Lund, Sweden, 2004.

(c)

(C) 2019 by the authors. Licensee MDPI, Basel, Switzerland. This article is an open access article distributed under the terms and conditions of the Creative Commons Attribution (CC BY) license (http://creativecommons.org/licenses/by/4.0/). 